\title{
A potência da experimentação investigativa no estudo de Gases: resultados de uma pesquisa que transcende a práticas demonstrativas
}

\section{The power of investigative experimentation in the study of Gases: results of a research that transcends demonstrative practices}

\author{
Lacordaire Kemel Pimenta Cury ${ }^{1}$, Paulo Vitor Teodoro ${ }^{2 *}$
}

\begin{abstract}
RESUMO
Este estudo foi desenvolvido junto ao Programa de Apoio à Pesquisa em Educação (Paped) do Instituto Federal Goiano (IF Goiano), no qual incentiva as investigações no campo educacional, inclusive valorizando a busca de inovação pedagógica, assim como as reflexões sobre essas práticas. Para tanto, esta pesquisa foi norteada pelo questionamento, apontado em pesquisas como a Hodson (1992), Flores, Sahelices e Moreira (2009) e Amauro, Souza e Mori (2015), sobre os possíveis impactos que a experimentação, no ensino de Ciências, pode alcançar. Desta forma, o presente artigo objetiva-se em apresentar resultados a partir de uma aula experimental investigativa, sobre o estudo dos gases. Para tanto, realizamos a reestruturação de um experimento, de natureza demonstrativa, sobre o comportamento dos gases, mostrado na Lei de Charles. Buscamos superar um ensino teórico e expositivo, baseado em regras e fórmulas, valorizando a participação dos estudantes. Pudemos considerar que um experimento demonstrativo pode ser aprimorado, com vistas à investigação, o que possibilita o desenvolvimento de habilidades, no processo de aprendizagem, que vão além da memorização e demonstração de teorias.
\end{abstract}

Palavras-chave: Estudo dos gases; Experimentação; Ensino de Ciências.

\section{ABSTRACT}

This study was developed with the Support Program for Research in Education (Paped, in Portuguese) of the Federal Institute of Goiano (IF Goiano - Brazil), which encourages investigations in the educational field, including valuing the search for pedagogical innovation, as well as reflections on these practices. Therefore, this research was guided by questioning, pointed out in researches such as Hodson (1992), Flores, Sahelices and Moreira (2009) and Amauro, Souza and Mori (2015), on the possible impacts of experimentation on the teaching of Science, can reach. Thus, this article aims to present results and reflections, from an investigative experimental class, on the study of gases. Therefore, we restructured an experiment, of a demonstrative nature, on the behavior of gases, shown in Charles' Law. Later, we applied the proposal with students from the IF Goiano, in the city of Catalão. We seek to overcome theoretical and expository teaching, based on rules and formulas, valuing the effective participation of students. To reach the proposition, we used a qualitative approach, based on action research. We could consider that a demonstrative experiment can be improved, with a view to investigation, which enables

\footnotetext{
${ }^{1}$ Instituto Federal de Educação, Ciência e Tecnologia Goiano (IF Goiano) - Campus Catalão.

2 Universidade Federal de Uberlândia (UFU)/ Programa de Pós-Graduação (Mestrado) em Ensino de Ciências e Matemática/UFU.

*E-mail do autor responsável pela submissão: paulovitorteodoro@ufu.br
} 
the development of skills, in the learning process, that go beyond memorization and demonstration of theories.

Keywords: Study of gases; Experimentation; Science teaching.

\section{INTRODUÇÃO}

Pesquisas na área de educação em Ciências, apontam as mais diversas dificuldades para implementação de um ensino que seja, de fato, efetivo em sala de aula (ANDRADE e MASSABNI, 2011; MORAES e SILVA JUNIOR, 2014; SOUZA, SILVEIRA e LONGHINI, 2015). Especialmente as aulas de Química e Física do ensino médio, os conteúdos são trabalhados, geralmente, de forma tradicional e expositivo (VIEIRA, 2014). Assim, quase sempre, o referido ensino fica distante da realidade vivenciada pelos discentes.

O dinamismo da sociedade moderna faz com que a aprendizagem mecânica, a simples memorização de conceitos e fórmulas, perca seu sentido. Para Moreira (2014, p.1-2): "A Física na Educação Básica está em crise. Estamos no século XXI, mas a Física ensinada não passa do século XIX”.

Dentre as principais causas da defasagem do ensino de Ciências, são apontadas a falta de preparo dos professores, as más condições de trabalho, a reduzida carga horária dedicada à disciplina, a perda de identidade de um currículo desatualizado, bem como a aprendizagem, que se dá de forma mecânica (MOREIRA, 2014; VIEIRA, 2014).

O distanciamento entre o conteúdo das Ciências Naturais (Física, Química, Biologia e Geociências) e as inter-relações entre o cotidiano, as aplicações e a formação cidadã dos estudantes, é um fator preocupante no ensino de Ciências. Mayer et. al. (2013), Rodrigues; Santos; Times (2015), entre outros, reconhecem que o ensino das ciências naturais encontra como um dos obstáculos o distanciamento entre conteúdo e cotidiano e, assim como Moreira (2014), atribuem parte da responsabilidade ao preparo inadequado dos professores em conjunto com projetos pedagógicos que não favorecem essa interação. Segundo Mayer, et al (2013):

A aplicação das matérias, como a de ciências naturais em muitos lugares ainda é transmitida de forma diminuída, o modelo de interação aluno/conteúdo, não é totalmente aceita por alguns professores devido a fatores, como: maior ocupação do seu tempo e maior dedicação do mesmo com novos métodos didáticos. [...] É necessário, que o ensino de ciências esteja ligado diretamente com o mundo do aluno, ou seja, 
que ele possa vir a extrair do ensino de ciências e aplicar no seu cotidiano (MAYER et. al., 2013, p. 231).

A Química e a Física, embora sejam entendidas como uma ciência que estuda a Natureza e seus fenômenos, poucas vezes é identificada, pelos estudantes, presente em nosso universo. A Mecânica, a Óptica, as Reações Químicas, a Termodinâmica estão presentes por toda a parte, mas, entretanto, a forma como esses assuntos são ministrados em sala de aula, prejudica o seu reconhecimento como uma ciência imprescindível para formação de pessoas mais instruídas, críticas e reflexivas sobre o ambiente natural.

Segundo José e Bastos (2017, p. 49), "para estruturar o conhecimento físico escolar, é necessário os elementos do mundo vivencial dos estudantes em conexão com ações e intervenções concretas na sala de aula". Sendo assim, as aulas de Ciências:

devem possibilitar aos alunos a compreensão das transformações químicas que ocorrem no mundo físico de forma abrangente e Integrada para que possam julgar, com fundamentos, as informações adquiridas na escola e tornarem cidadãos participantes (SEVERO; KASSEBOEHMER, 2017, p.109).

O formato que se ancora no modelo de um ensino tradicional não mais atende às demandas da sociedade moderna e da preparação para a cidadania plena, participativa e reflexiva.

\begin{abstract}
As características de nossa tradição escolar diferem muito do que seria necessário para a nova escola. De um lado, essa tradição compartimenta disciplinas em ementas estanques, em atividades padronizadas, não referidas a contextos reais. De outro lado, ela impõe ao conjunto dos alunos uma atitude de passividade, tanto em função dos métodos adotados quanto da configuração Física dos espaços e das condições de aprendizado. Estas, em parte, refletem a pouca participação do estudante, ou mesmo do professor, na definição das atividades formativas. As perspectivas profissional, social ou pessoal dos alunos não fazem parte das preocupações escolares; os problemas e desafios da comunidade, da cidade, do país ou do mundo recebem apenas atenção marginal no ensino médio, que também por isso precisaria ser reformulado (BRASIL, 2002, p. 9).
\end{abstract}

As críticas se estendem, segundo Moreira (2014), a criação de novos paradigmas educacionais, uma reforma que promova competências gerais, que articule conhecimentos e que permita ao alunado o pleno desenvolvimento de seu potencial. No sentido de superar o modelo tradicional de ensino, centralizado no professor e descontextualizado do cotidiano do educando, há cerca de quatro décadas vem 
ocorrendo um crescente movimento de reaproximação entre ciência e sociedade, provocada pela disseminação de novas tecnologias e também por uma nova consciência sobre as interações entre o homem e a natureza (SANTOS, 2007, p. 1).

Essa nova percepção encontra reflexo nos documentos oficiais do Ministério da Educação já há algum tempo. Os Parâmetros Curriculares Nacionais (PCN) para o ensino de Ciências Naturais, por exemplo, publicado em 1997, já afirmava que:

\begin{abstract}
A formação de um cidadão crítico exige sua inserção numa sociedade em que o conhecimento científico e tecnológico é cada vez mais valorizado. Neste contexto, o papel das Ciências Naturais é o de colaborar para a compreensão do mundo e suas transformações, situando o homem como indivíduo participativo e parte integrante do Universo (BRASIL, 1997, p. 15).
\end{abstract}

As Diretrizes Curriculares Nacionais Gerais para a Educação Básica, publicadas em 2013, também apontam um ensino de Ciências visando a formação ampla dos estudantes, no sentido de compreenderem os valores em que se fundamenta a sociedade (BRASIL, 2013).

Autores, como Mayer et. al. (2013), sugerem que a implementação de um ensino mais democratizado, capaz de pensar a formação crítica e pleno do educando, perpassa por diversos processos, incluindo uma melhor formação do professor e a reformulação das propostas pedagógicas, diversificando as opções didáticas e seu formato de apresentação. Para que isso ocorra, é necessário que haja um repertório de metodologias que possam ser escolhidas de acordo com cada situação, ampliando as opções do professor para estimular o engajamento dos alunos.

A contextualização e articulação entre os conhecimentos de Ciências são palavras-chave para se pensar em propostas de intervenção pedagógica que tenha como foco o aprendizado dos estudantes. Especificamente no que se refere às Ciências Naturais (Química, Biologia, Física e Geociências), as propostas apresentadas dirigemse para mudanças na didática dos conteúdos, de maneira a ampliar a participação dos aprendizes e a compreensão, em oposição à passividade e a memorização que caracterizam o ensino tradicional.

A distinção entre modelo e realidade, entre interpretação e fenômeno, o domínio dos conceitos de interação e de função, de transformação e conservação, de evolução e identidade, de unidade e diversidade, de equivalência e complementaridade, não são prerrogativas desta ou 
daquela ciência, são instrumentos gerais, desenvolvidos em todo o aprendizado científico, que promovem, como atributo da cidadania, a competência geral de investigação e compreensão (BRASIL, 2002, p. 25).

Esse modelo de educação exige dos docentes um preparo diferenciado, metodologias que valorizam os educandos no processo de ensino-aprendizagem de ensino, que, segundo Moreira (2014), ainda não são a prática comum nas escolas. Rodrigues et. al. (2015) afirmam, ainda, que as Ciências, especialmente a Física e a Química, são consideradas disciplinas de difícil aprendizado, quando não se apropria da estrutura fenomenológica .

\begin{abstract}
A Física está em todo lugar, no cotidiano das pessoas, é uma ciência fantástica que deveria fascinar quem a estuda, mas é uma das disciplinas mais temidas pelos alunos, principalmente do ensino médio, com uma alta dose de frustração, insegurança e resistência ao ensino de Física (RODRIGUES; SANTOS; TIMES, 2015, p. 58).
\end{abstract}

Desse modo, evidencia-se um dos desafios atuais na Educação: aproximar a teoria da prática, o conteúdo estudado das atividades diárias dos alunos, proporcionando a construção de uma consciência crítica que conduzirá à cidadania. É preciso ressaltar que, muitas vezes,

em Física, onde o ensino é desenvolvido com base no uso de fórmulas e equações, além de leis, princípios e conceitos isolados, a aprendizagem, por consequência, ocorre de forma mecânica, estéril e desvinculada do mundo vivenciado pelo estudante, proporcionandolhe condições que, na maioria das vezes, apenas lhe permite repetir os enunciados das leis sem entender os significados dos conceitos e resolver mecanicamente, com o uso das expressões matemáticas, os problemas propostos no livro texto (ANJOS; MOREIRA; SAHELICES, 2015, p.313).

O ensino de Ciências supõe a produção de conhecimentos que devem ir além de conceitos formulados, ficando restrito ao contato teórico com os variados temas dos seus conteúdos. Nesse sentido, as atividades experimentais podem constituir uma rica estratégia para incentivar os estudantes para o estudo de conteúdos relacionados à Física e à Química.

As atividades experimentais, tanto no ensino médio como em muitas universidades, ainda são muitas vezes tratadas de forma acrítica e 
aproblemática. Pouca oportunidade é dada aos alunos no processo de coleta de dados, análise e elaboração de hipóteses. O professor é o detentor do conhecimento e a ciência é tratada de forma empírica e algorítmica. $\mathrm{O}$ aluno é o agente passivo da aula e a ele cabe seguir um protocolo proposto pelo professor para a atividade experimental, elaborar um relatório e tentar ao máximo se aproximar dos resultados já esperados (SUART; MARCONDES, 2009, p.51).

A correlação entre teoria e atividade prática constitui uma forma de ministrar conteúdos de Ciências na Educação Básica, fornecendo mais elementos, argumentos e fatos, que, em conjunto com outros conhecimentos, podem ajudar na compreensão e construção de conceitos científicos (SOUZA, et. al., 2015). As considerações explanadas neste texto, nortearam a problemática da presente pesquisa, na medida em que teve como questionamento: como a experimentação pode colaborar para promover o aprendizado dos estudantes no ensino de gases?

Diante do exposto, este artigo tem como objetivo geral, apresentar resultados de uma proposta de pesquisa que buscou investigar as possibilidades de se realizar um ensino de Ciências, na Educação Básica, que supere ações expositivas, memorísticas, baseadas em fórmulas e regras. Para tanto, apropriamos da experimentação para desenvolver ações pedagógicas a partir do conteúdo de gases.

Os objetivos específicos da pesquisa buscaram aplicar a experimentação, fazendo simulação do comportamento dos gases, mostrado na Lei de Charles; trabalhar o conteúdo de gases, indo além do ensino tradicional, superando abordagens teóricas e expositivas; identificar as contribuições da atividade prática para envolvimento e aprendizagem discente; e, ainda, destacar a importância da experimentação nas aulas de Ciências. A coleta de dados foi realizada em uma escola pública da cidade de Catalão, Goiás, com estudantes da segunda série do Ensino Médio.

\section{METODOLOGIA}

A metodologia proposta para realização do trabalho se baseou na pesquisa-ação. Essa metodologia de pesquisa possibilita a produção de conhecimentos novos e formação de sujeitos pesquisadores, críticos e reflexivos, pois os próprios pesquisadores participam, efetivamente, de todo o processo da investigação (BARBIER, 2002). A pesquisa-ação é um tipo de metodologia em que os proponentes pesquisadores são participantes do processo e que, diante de uma problemática, juntamente com os outros 
envolvidos, refletem sobre as causas e/ou efeitos da situação, no sentido de elaborar medidas para resolver ou amenizar os problemas identificados (SOUZA, 2014).

A pesquisa foi desenvolvida em quatro fases. A primeira, de caráter bibliográfico, realizamos uma sobre o atual contexto do ensino da Ciências na Educação Básica, visando obter subsídios que permitam identificar as metodologias didáticas utilizadas e seus reflexos na aprendizagem dos alunos.

A segunda, de caráter analítico, fez fizemos um estudo sobre os resultados obtidos na primeira fase e suas aproximações ou distanciamentos com o currículo proposto para as Ciências (Física e Química), mais especificamente para o conteúdo relacionado ao estudo dos gases.

A terceira fase, experimental, buscamos encontrar possibilidades de abordagem para o tema "Gases", utilizando os conhecimentos adquiridos nas fases anteriores, apresentando propostas e metodologias que facilitem o processo de ensinoaprendizagem, dentro das diretrizes já levantadas.

A quarta e última fase refere-se à aplicação das sugestões elaboradas, por meio de pesquisa de campo, com avaliação qualitativa de sua eficácia no processo de ensinoaprendizagem. Desse modo, aplicamos um experimento para simular o comportamento dos gases mostrado na Lei de Charles. Apresentando assim, de forma clara, a transformação isobárica do gás, na qual é conservada a pressão interna, e a modificação do volume é mostrada diretamente de acordo com a variação da temperatura.

\section{RESULTADOS E DISCUSSÃO}

Por meio da proposta de pesquisa no Ensino de Ciências, a qual buscamos realizar intervenções na educação básica, com o intuito de superar aulas expositivas, memorísticas e conteudistas, buscamos triangular os resultados encontrados e apontar diagnósticos, imprescindíveis, para avançarmos na educação em Ciências em nosso país.

Inicialmente, buscamos reestruturar experimentos que já são utilizados, inclusive em livros didáticos de Ciências (Física e Química). Um grande problema de muitos experimentos é que esses vem com o intuito de demonstrar ou comprovar alguma teoria. A experimentação utilizada nesse viés, pouco contribui para a formação do alunado (HODSON, 1992; FLORES, SAHELICES e MOREIRA, 2009; AMAURO, SOUZA e 
MORI, 2015). Diante disso, Lima (2013), Suart et al (2015), Souza et. al. (2015), entre outros, já apontam uma visão mais ampla da experimentação, no sentido de inserir os estudantes para resolverem situações problemas por meio da experimentação e, a partir disso, chegarem ao conhecimento. Isso significa que a experimentação deixará de ser uma ferramenta de aprendizagem, para ser um recurso potencial e necessário para o ensino de conceitos de Ciências.

Se por um lado ações demonstram a teoria, geralmente ensinada em sala de aula, a experimentação investigativa insere os estudantes na resolução de problemas, propicia a autonomia para tomada de decisões, desenvolve habilidades cognitivas nos estudantes, favorece o trabalho colaborativo para chegarem em conclusões e propicia a participação ativa dos discentes no processo de ensino e aprendizagem.

O primeiro experimento que utilizamos, foi encontrado no livro didático, intitulado Química: meio ambiente, cidadania, tecnologia (FONSECA, 2010). O experimento sugere a utilização para a intervenção demonstrativa. Para enriquecermos a ação, fizemos alterações no experimento de modo que a experimentação pudesse ter um impacto ainda maior no aprendizado dos estudantes. Diante disso, utilizamos a seguinte questão problema: como a temperatura influencia na contração ou expansão dos gases?

Para resolver essa questão, solicitamos aos estudantes que fizessem grupos de quatro estudantes. Em cada grupo, disponibilizamos materiais, como três (3) garrafas pet de 600 ml, 3 balões, água no ponto de ebulição, água gelada, dois recipientes (jarras de vidro) e funil de vidro. Explicitamos, com o intuito de direcionarmos a atividade, que os discentes poderiam utilizar os materiais disponibilizados nos grupos e, uma possibilidade, seria trabalhar com os balões em contato com as garrafas cheias de águas, em diferentes temperaturas.

O primeiro resultado que acreditamos ser importante foi o envolvimento dos estudantes, caracterizados pelos embates de ideias, verbalização e questionamentos reflexivos durante a aula. Perguntas do tipo: "Professor, mas como vou fazer isso? Professor, a gente não sabe o que precisa fazer primeiro?’. Ações dessa natureza mostram que os discentes não estão acostumados com propostas em que eles buscam os resultados. Atualmente, nas escolas brasileiras, as informações são colocadas de forma pronta, sem oportunidades para discussão. E, assim, dificilmente existirá construção (formação) de conhecimento. 
Após a euforia inicial, percebemos que os estudantes discutiam em possibilidades para mostrar efeitos nos balões. Um dos grupos colocou água gelada dentro do balão, mas nada foi observado. Quando colocou água quente, também percebeu que nada aconteceu. Ou seja, essa estratégia de inserir água no balão, não chegaria a nenhum propósito naquele instante. Enquanto isso, os outros grupos também discutiam buscando possibilidades de apontar efeitos nos balões, ou mesmo nas garrafas.

Nisso, o professor da disciplina sugeriu outra dica: “mas, e se deixassem o balão na boca da garrafa e inserissem esse sistema em diferentes temperaturas?" Após essa dica, os estudantes, em grupos, começaram a avançar na investigação e frases do tipo eram ouvidas: "ah, por isso tem água quente e gelada" "olham, tem água gelada nessa vasilha [recipiente de vidro] e água quente nessa outra”.

Após esse direcionamento, os estudantes buscaram encontrar soluções a partir da inserção do balão na boca da garrafa, em diferentes temperaturas. Percebemos que todos os grupos seguiram na mesma linha de raciocínio, muito embora, esperávamos que surgissem outras perspectivas para confrontamento de ideias com o professor. Infelizmente, isso não aconteceu, talvez por ainda estarem se adaptando com intervenções, baseada na experimentação investigativa, em que eles são protagonistas do aprendizado.

Souza e Bhering (2016), a partir de um relato de pesquisa sobre o protagonismo estudantil, discutem o impacto que tem, na formação integral do estudante, ações que dão vozes e autonomia para eles. Ao mesmo tempo, os autores apontam as dificuldades em romper o paradigma de que o professor não precisa, e nem deve, ser o centro das atenções em sala de aula. E, na pesquisa apresentada neste texto, reafirmamos as dificuldades em inserir os discentes como protagonistas das atividades.

Percebemos que dar voz ao estudante é complexo por dois motivos: o primeiro porque não fomos devidamente preparados para isso. Fomos ensinados que o professor é o detentor do saber e que o aprendiz, precisa apenas ouvir e aceitar o que está sendo ensinado; o segundo motivo, se refere ao fato de que é extremamente complexo sairmos da zona de conforto. Uma aula em que apenas o professor expõe o conteúdo, não abre muitas oportunidades para embate de ideais; por outro lado, uma aula investigativa o estudante irá buscar soluções, sem um método único para isso. Assim, o docente precisa 
ter habilidades para conduzir tais propostas e, quando não for possível, estar disposto a buscar respostas para tais inquietações.

Notamos que alguns grupos mergulharam a garrafa com o balão na água quente e outros na água fria. Logo já percebemos sinais de que algumas observações estavam sendo evidenciadas. Posteriormente, cada grupo apresentou uma solução para a questão inicial. No Quadro 1, segue algumas proposições que os grupos apresentaram para os fenômenos:

Figura 1 - Proposições apresentadas em sala de aula.

\begin{tabular}{|c|c|}
\hline & Proposições para a problematização inicial \\
\hline Grupo 1 & $\begin{array}{l}\text { "se colocar a garrafa com o balão na água quente, o } \\
\text { balão vai encher, porque os gases sobem e o balão } \\
\text { enche". } \\
\text { "se colocar a garrafa com o balão na água fria, os gases } \\
\text { ficam embaixo e o balão murcha". }\end{array}$ \\
\hline Grupo 2 & $\begin{array}{l}\text { "na água quente esquenta a garrafa e o balão enche". } \\
\text { "na água fria é o contrário, por isso o balão murcha". }\end{array}$ \\
\hline Grupo 3 & $\begin{array}{l}\text { "o balão vai encher se estiver na água quente, porque as } \\
\text { moléculas de água agitam" } \\
\text { "na água fria é o contrário. Como terá pouca agitação } \\
\text { das moléculas, a bexiga murcha" }\end{array}$ \\
\hline Grupo 4 & $\begin{array}{l}\text { "se estiver quente, expande o ar e o ar sobe, por isso } \\
\text { enche o balão" } \\
\text { "agora, na água fria, não expande o ar e por isso } \\
\text { murcha" }\end{array}$ \\
\hline
\end{tabular}

Fonte: autoria própria (2021)

Percebemos que os grupos utilizam termos do senso comum para descrever os fenômenos. Isso é um fator importantíssimo, especialmente porque eles ainda não tem arcabouço teórico, com vocabulário científico adequado para descreverem os fenômenos. Entretanto, os educandos possuem conhecimentos prévios, mesmo que do senso comum, que corrobora para a explicação das transformações. E, é função do professor, oportunizar espaços durante a aula para que aconteça o desenvolvimento dos discentes. Diante disso, após os grupos apontarem os resultados, o professor explicou os fenômenos, embasando nas proposições que eles apontaram, juntamente com explicações científicas. Ou seja, o professor trouxe o conteúdo científico, apropriando das concepções que os aprendizes tinham sobre os fenômenos.

O professor discutiu que, se o sistema (balão e garrafa PET) for inserido em água quente, realmente aconteceria a expansão dos gases e o balão iria encher, como os 
grupos apontaram. Isso pelo fato da agitação das moléculas gasosas que existem no interior da garrafa. E, se tem a agitação das moléculas, a tendência é que os gases se dissipem, colaborando para o balão encher.

O professor também discutiu quando o sistema é colocado em um recipiente com água fria. O docente valorizou as respostas dos estudantes, quando aponta que, de fato, o balão murcha. Isso a temperatura diminui e, consequentemente, o volume dos gases, no interior da garrafa, são contraídos. Com isso, o balão murchará.

As ações referidas vão ao encontro das prerrogativas do Ministério da Educação (MEC) que em 2013 divulgou o documento das Diretrizes Curriculares Nacionais Gerais para a Educação Básica, visando atualizar os documentos oficiais, de acordo com o estabelecido pela Lei de Diretrizes e Bases da Educação Nacional (Lei n. ${ }^{\circ}$ 9.394/96). As principais mudanças referem-se ao reconhecimento do ensino médio, como uma etapa da Educação que não deve se restringir ao preparo para o seguimento dos estudos em nível superior, mas sim para a formação de cidadania e capacitar os estudantes para o aprendizado permanente, em prosseguimento dos estudos posteriores ou mundo do trabalho (BRASIL, 2013).

Destaca-se assim, o reconhecimento de que o formato tradicional de ensino, não mais atende às demandas da sociedade moderna e da preparação para a cidadania plena, participativa e reflexiva. Além da consideração sobre a vivência dos discentes, Severo e Kasseboehmer (2017) assinalam que é importante que se sintam parte de um processo educativo, voltados para aprender Ciências, especialmente a Física e a Química.

A cultura de escolas tradicionais apresenta características muito diferentes da ações metodologias e estratégias necessárias para a escola atual, pois aquela primeira se trilha por posturas rígidas sem contextualização com a realidade dos discentes, não contribuindo de modo efetivo para o desenvolvimento do ensino e da aprendizagem escolar (BRASIL, 2013).

As críticas se estendem, segundo Moreira (2014), a criação de novos paradigmas educacionais, uma reforma que promova competências gerais, que articule conhecimentos e que permita ao aluno o pleno desenvolvimento de seu potencial.

A contextualização e articulação entre os conhecimentos são palavras-chave para a nova educação proposta pelas Diretrizes Curriculares Nacionais. Especificamente no que se refere às Ciências Naturais (Biologia, Física, Geociências e Química), as propostas apresentadas dirigem-se para mudanças na didática dos temas, de maneira a 
ampliar a participação dos estudantes e a compreensão, em oposição à passividade e a memorização que caracterizam o ensino tradicional (BRASIL, 2002).

Esse formato exige dos docentes um preparo diferenciado, metodologias inovadoras de ensino e, que, segundo Moreira (2014), ainda não constituem prática comum nas escolas brasileiras. Exige, também, a desconstrução de velhos e errôneos conceitos, que prejudicam a aprendizagem e ainda são obstáculos para alunos e professores. Deste modo, percebemos que não basta o professor ter conhecimento pedagógico sobre o que ensinar, nem tampouco, conhecimentos específicos de conteúdos escolares. É preciso habilidades e competências necessárias para o exercício complexo da docência, que vão desde a formação inicial de professores até a experiência profissional adquirida durante a trajetória do docente. Assim como, é fundamental, também, a formação contínua do professorado em momentos que possibilitam a reflexão sobre a prática pedagógica.

Rodrigues, Santos e Times (2015) afirmam que associado aos desafios relacionados ao ensino da Ciências/Física ainda está o fato da disciplina ser considerada “difícil”. No entanto, as Ciências (Física, Química, Biologia e Geociências) faz parte do cotidiano das pessoas, encontra-se em todo lugar e é fundamental ter conhecimentos, mesmo que iniciais/básico, para que possa ter condições de tomada de decisão consciente, sabedoria para resolver situações presentes em nosso dia a dia, garantir a utilização correta do nosso meio, entre outros fatores. O que apontamos é que pessoas com conhecimento sobre a ciência são colaboradores de um mundo melhor.

\section{CONCLUSÕES}

A realização de aplicação de atividade experimentais no ensino de gases, por meio de uma ação prática simulando o comportamento dos gases, evidenciou-se que a experimentação constitui uma potencial estratégia para que o aluno se torne um agente ativo no processo de construção de conhecimentos. Isso significa que de espectador, o estudante passa a ter a função de principal no processo de ensino e aprendizagem.

$\mathrm{O}$ estudo demonstra que as atividades experimentais possibilitam que o aluno seja incitado a não permanecer no mundo dos conceitos tendo a oportunidade de relacioná-los ao mundo empírico. Dessa maneira, as atividades experimentais auxiliam na consolidação do conhecimento e no desenvolvimento cognitivo do aluno. Agrega benefícios no processo de ensino e aprendizagem de Ciências, pois a vivência de 
situações reais é de grande importância para a compreensão e correlação dos diversos temas. No entanto, é preciso ter alguns cuidados para que a experimentação seja além de uma ferramenta de ensino. Precisamos entender a experimentação como estratégia potencial para a formação cidadã dos aprendizes.

Percebemos que os educandos conseguiram questionar o mundo, refletir sobre modelos, desenvolver métodos e chegar ao conhecimento quando ele é posto como sujeito ativo na aprendizagem. Deste modo, a pesquisa em educação em Ciências, com a intenção (e necessidade) de elaboração de novas propostas didáticas, tem sido incessante [conforme mostram Barbosa e Pio (2021), Costa (2020), entre outros], pois as novas diretrizes educacionais exigem uma reformulação das práticas pedagógicas, o que necessariamente passa pela reestruturação dos instrumentos didático-pedagógicos.

Notamos que por mais simples que o experimento ou estratégia didática que o professor utilizar em sala de aula, diferente da exposição de conteúdos, poderá ser instigado a curiosidade e questionamentos sobre o tema, gerando oportunidade discente para correlacionar a aprendizagem escolar com sua vivência cotidiana, ação necessária à formação do indivíduo com autonomia e criticidade, aspectos elementares para a cidadania.

\section{REFERÊNCIAS}

AMAURO, N. Q.; SOUZA, P. V. T.; MORI, R. C.; As funções pedagógicas da experimentação no ensino de Química. Multi-Science Journal, v. 1, n. 3, 2015.

ANDRADE, M. L. F.; MASSABNI, V. G. O desenvolvimento de atividades práticas na escola: um desafio para os professores de ciências. Ciência \& Educação, v. 17, n. 4, p. 835-854, 2011.

ANJOS, A. J. S.; SAHELICES, C.C.; MOREIRA, M.A. As equações matemáticas no ensino de Física: Uma análise de conteúdos em livros didáticos de Física. Revista Electrónica de Enseñanza de las Ciencias, v. 14, n. 3, p. 312-325, 2015.

BARBIER, R. A pesquisa-ação. Trad. Lucie Didio. Brasília: Plano Editora, 2002.

BARBOSA, M. S.; PIO, J. L. S. Aprendizagem de modelos atômicos em atividades colaborativas com mapeamento da zona de desenvolvimento proximal em jogos móveis. Revista Conjecturas, v. 21, n. 4, p. 677-697, 2021.

BRASIL. Ministério da Educação. Secretaria de Educação Básica. Secretaria de Educação Continuada, Alfabetização, Diversidade e Inclusão. Conselho Nacional da Educação. Diretrizes Curriculares Nacionais Gerais da Educação Básica/ Ministério da Educação. Secretária de Educação Básica. Diretoria de Currículos e Educação Integral. Brasília, DF: MEC, SEB, DICEI, 2013. 
BRASIL. MINISTÉRIO DA EDUCAÇÃO. Secretaria de Educação Fundamental. Parâmetros Curriculares Nacionais - Ciências Naturais. Brasília: MEC, 1997.

BRASIL. MINISTÉRIO DA EDUCAÇÃO. Secretaria de Educação Básica. Parâmetros Curriculares Nacionais - Ensino Médio - Ciências da Natureza, Matemática e suas Tecnologias. Brasília: MEC, 2002.

BRASIL. MINISTÉRIO DA EDUCAÇÃO. Lei de Diretrizes e Bases para Educação Nacional. Lei n. 9.394/96 DE 20 de Dezembro, 1996. Estabelece as diretrizes e bases da educação nacional. Brasília, $1996 . \quad$ Disponível em: <http://www.planalto.gov.br/ccivil_03/leis/L9394.htm>. Acesso em: 19 maio 2016.

COSTA, B. B. Ensino de matemática remoto: uma experiência inédita na educação básica. Revista Conjecturas, v. 20, n. 1, p. 44-60, 2020.

FLORES, J.; SAHELICES, M. C. C.; MOREIRA, M. A. El laboratorio en la enseñanza de las ciencias: una visión integral en este complejo ambiente de aprendizaje. Revista de Investigación, Caracas, v. 33, n. 68, p. 75-111, 2009.

FONSECA, M. R. M. Química: meio ambiente, cidadania, tecnologia. 1. Ed. - São Paulo: FTD, 2010. - (Coleção química, meio ambiente, cidadania, tecnologia: v.2).

HODSON, D. Assessment of practical work: some considerations in philosophy of science. Science \& Education, v. 1, n. 2, p. 115-144, 1992.

JOSÉ, W. D.; BASTOS, F. da P. Trabalho colaborativo no ensino de Física mediado por tecnologias educacionais em rede para resolução de problemas. Revista Electrónica de Enseñanza de las Ciencias, v. 16, n. 1, p. 47-68, 2017.

KRASILCHIK, M. Reformas e Realidade: o caso do ensino das ciências. São Paulo em Perspectiva, v. 14, n. 1, p. 85-93, 2000.

LIMA, Viviani Alves de. Um Processo de Reflexão Orientada Vivenciado por Professores de Química: O Ensino Experimental como Ferramenta de Mediação. 2013. 257 f. Tese (Doutorado em Ensino de Química) - Ensino de Ciências (Física, Química e Biologia), Universidade de São Paulo, São Paulo, 2013.

MAYER, K. C. M. et al. Dificuldades Encontradas na Disciplina de Ciências Naturais por Alunos do Ensino Fundamental da Escola Pública da Cidade de Redenção - PA. Revista Lugares de Educação, Bananeiras (PB), v. 3, n. 6, p. 230-241, Jul.-Dez., 2013.

MORAES, J. U. P.; SILVA JUNIOR, R. S. Experimentos didáticos no ensino de física com foco na aprendizagem significativa. Aprendizagem Significativa em Revista, v. 4, n. 3, p. 6167, 2014.

MOREIRA, M. A. Grandes Desafios para o Ensino da Física na Educação Contemporânea. In: Ciclo de Palestras dos 50 anos do Instituto de Física da UFRJ, 2014, Rio de Janeiro. Conferência. Rio de Janeiro: UFRJ, 2014. Disponível em: $<$ http://www.if.ufrj.br/ pef/aulas_seminarios/seminarios/2014_Moreira_DesafiosEnsinoFisica.p df>. Acesso em: 19 maio 2016.

RODRIGUES, R. F.; SANTOS, J. C. S.; TIMES, K. S. Ensino e Aprendizagem de Física em Questão: estratégias e potencialidades pedagógicas de uma metodologia diferenciada. Revista Eletrônica Sala de Aula em Foco, Vitória (ES), v. 4, n. 1, p. 58-67, 2015. 
SANTOS, W. L. P. Contextualização no Ensino de Ciências por Meio de Temas CTS em uma Perspectiva Crítica. Ciência \& Ensino, Piracicaba (SP), v. 1, n. Especial, nov. 2007. Disponível em: 〈http://prc.ifsp.edu.br/ojs/index.php/cienciaeensino/issue/view/15>. Acesso em: 15 maio 2016.

SEVERO, I. R. M.; KASSEBOEHMER, A. C. Estudo do perfil motivacional de estudantes da educação básica na disciplina de Química. Revista Electrónica de Enseñanza de las Ciencias. v. 16, n. 1, p. 94-116, 2017.

SOUZA, P. V. T; BHERING, M. J. O protagonismo estudantil na elaboração de propostas pedagógicas na escola: avaliação de um estudo de caso. Ciclo Revista: experiências em formação no IF Goiano, v. 2, n.1, p. 168-173, 2016.

SOUZA, P. V. T.; SILVA, M. D.; AMAURO, N. Q.; MORI, R. C.; MOREIRA, P. F. S. Densidade: uma proposta de aula investigativa. Revista Química Nova na Escola, v. 37, n. 2, 2015.

SOUZA, P. V. T.; SILVEIRA, H. E.; LONGHINI, I. M. M. A busca de um projeto interdisciplinar com foco na educação ambiental. Revista Enciclopédia Biosfera, Centro Científico Conhecer, v. 11, n. 20, p. 14-25, 2015.

SOUZA, P. V. T. Trajetória da construção de um projeto interdisciplinar na escola: em foco a Educação Ambiental. 2014. 117 f. Dissertação (Mestrado em Ensino de Ciências) Instituto de Instituto de Física, Instituto de Química, Faculdade de Ciências Integradas do Pontal e Faculdade de Matemática, Universidade Federal de Uberlândia, Uberlândia. 2014.

SUART, R. C.; ABRAS, C. M.; MACULAN, D. S.; PEDROSO, J. R.; ROSA, L. M. R.; MIRANDA, M. S.; BERNARDO, R. A.; MARCONDES, M. E. R. Uma análise do desenvolvimento de sequências de aulas por licenciandas de química ao longo de um processo de reflexão orientada. Investigações em Ensino de Ciências, v. 20, n. 2, p. 186-208, 2015.

SUART, R. C.; MARCONDES, M. E. R. A manifestação de habilidades cognitivas em atividades experimentais investigativas no ensino médio de química. Ciência \& Cognição, 14 (1), 2009. p. 50-74.

VIEIRA, A. S. Uma alternativa didática às aulas tradicionais: o engajamento interativo obtido por meio do uso do método peer instruction (instrução pelos colegas). 2014. $235 \mathrm{f}$. Dissertação (Mestrado em Ensino de Física) - Instituto de Física, Universidade Federal do Rio Grande do Sul, Porto Alegre. 2014.

\section{Recebido em: 01/11/2021}

Aprovado em: 25/11/2021

Publicado em: 02/12/2021 